\title{
Antiplasmodial Properties and Cytotoxicity of Endophytic Fungi from Symphonia globulifera (Clusiaceae)
}

\author{
Joël E. T. Ateba ${ }^{1}$, Rufin M. K. Toghueo ${ }^{2}$, Angelbert F. Awantu ${ }^{3}$, Brice M. Mba'ning ${ }^{1, *}$, \\ Sebastian Gohlke ${ }^{4}$, Dinkar Sahal ${ }^{5}$, Edson Rodrigues-Filho ${ }^{6}$, Etienne Tsamo ${ }^{1}$, \\ Fabrice F. Boyom ${ }^{2}$ (D), Norbert Sewald 4 (D) and Bruno N. Lenta ${ }^{7, *}$ \\ 1 Department of Organic Chemistry, Faculty of Science, University of Yaoundé 1, P.O. Box 812, \\ 237 Yaoundé, Cameroon; atebaterence@yahoo.fr (J.E.T.A.); etsamo@yahoo.fr (E.T.) \\ 2 Department of Biochemistry, Faculty of Science, University of Yaoundé I, Cameroon; P.O. Box 812, \\ 237 Yaoundé, Cameroon; toghueo.rufin@yahoo.fr (R.M.K.T.); fabrice.boyom@fulbrightmail.org (F.F.B.) \\ 3 Department of Chemistry, Faculty of Science, University of Bamenda, P.O. Box 39, 237 Bambili, Cameroon; \\ aawantu@gmail.com \\ 4 Department of Chemistry, Organic and Bioorganic Chemistry, Bielefeld University, P.O. Box 100131, \\ D-33501 Bielefeld, Germany; sebastian.gohlke@uni-bielefeld.de (S.G.); \\ norbert.sewald@uni-bielefeld.de (N.S.) \\ 5 International Centre for Genetic Engineering and Biotechnology, Aruna Asaf Ali Marg, New Delhi 110067, \\ India; dsahal@gmail.com \\ 6 Departamento de Química-Universidade Federal de São Carlos-CP 676, São Carlos-SP 13565-905, Brazil; \\ edinho@pq.cnpq.br \\ 7 Department of Chemistry, Higher Teacher Training College, University of Yaoundé 1, P.O. Box 47, \\ 237 Yaoundé, Cameroon \\ * Correspondence: brice_mbaning@yahoo.fr (B.M.M.); lentabruno@yahoo.fr (B.N.L.); \\ Tel.: +2-3767-511-9805 (B.M.M.); +2-3767-509-7561 (B.N.L.)
}

Received: 27 April 2018; Accepted: 8 June 2018; Published: 12 June 2018

\begin{abstract}
There is continuing need for new and improved drugs to tackle malaria, which remains a major public health problem, especially in tropical and subtropical regions of the world. Natural products represent credible sources of new antiplasmodial agents for antimalarial drug development. Endophytes that widely colonize healthy tissues of plants have been shown to synthesize a great variety of secondary metabolites that might possess antiplasmodial benefits. The present study was carried out to evaluate the antiplasmodial potential of extracts from endophytic fungi isolated from Symphonia globulifera against a chloroquine-resistant strain of Plasmodium falciparum (PfINDO). Sixty-one fungal isolates with infection frequency of $67.77 \%$ were obtained from the bark of S. globulifera. Twelve selected isolates were classified into six different genera including Fusarium, Paecilomyces, Penicillium, Aspergillus, Mucor, and Bipolaris. Extracts from the 12 isolates were tested against PfINDO, and nine showed good activity $\left(\mathrm{IC}_{50}<10 \mu \mathrm{g} \cdot \mathrm{mL}^{-1}\right)$ with three fungi including Paecilomyces lilacinus $\left(\mathrm{IC}_{50}=0.44 \mu \mathrm{g} \cdot \mathrm{mL}^{-1}\right)$, Penicillium janthinellum $\left(\mathrm{IC}_{50}=0.2 \mu \mathrm{g} \cdot \mathrm{mL}^{-1}\right)$, and Paecilomyces sp. ( $\left(\mathrm{IC}_{50}=0.55 \mu \mathrm{g} \cdot \mathrm{mL}^{-1}\right.$ ) showing the highest promise. These three isolates were found to be less cytotoxic against the HEK293T cell line with selectivity indices ranging from 24.52 to 70.56. Results from this study indicate that endophytic fungi from Symphonia globulifera are promising sources of hit compounds that might be further investigated as novel drugs against malaria. The chemical investigation of active extracts is ongoing.
\end{abstract}

Keywords: malaria; chloroquine-resistant Plasmodium falciparum; Symphonia globulifera; endophytic fungi; antiplasmodial $\mathrm{IC}_{50}$; selectivity index 


\section{Introduction}

Malaria remains a major cause of morbidity and mortality with more than 3.3 billion people living worldwide in countries with ongoing transmission at risk [1]. In 2016, 91 countries reported a total of 216 million cases of malaria and 445,000 deaths. The most affected populations were located in tropical and subtropical regions of the world, particularly in sub-Saharan Africa and Southeast Asia, where almost $80 \%$ of malaria cases are caused by Plasmodium falciparum [1]. The widespread appearance of drug-resistant malaria parasites, even to newly developed second and third generation therapeutics such as artemisinin and its derivatives, makes the development of novel antimalarial drug treatments all the more urgent [2].

Natural products remain a consistent source of antimalarial drug leads, with the best examples being quinine and artemisinin that have acted as gifts of medicinal plants for victims of malaria. Therefore, investigating natural resources for antiplasmodial drug discovery continues to be one of the best scientific approaches that can lead to the identification of novel lead compounds against malaria [3]. Moreover, in comparison to other natural sources like plants, microorganisms are highly diverse but narrowly explored. Indeed, microbes often coexist with plants and animals making it difficult to assess if the real hosts of the promising metabolites identified are from higher organisms themselves or the tiny microbes residing in them. However, studies based on estimation of microbial populations have revealed that only about $1 \%$ of bacteria and $5 \%$ of fungi have been characterized and the rest remain unexplored for their potential to offer novel drugs against diverse diseases [4]. One of these groups being explored in recent times for their drug discovery potential is endophytic fungi from medicinal plants.

In fact, during the last 20 years it has been observed that much of the wealth of microbial biodiversity with novel biochemistry and secondary metabolite production resides in endophytic association with plant tissues [5]. Interest in such microorganisms, termed endophytes, increased immensely with the discovery of an endophytic fungus, from Taxus brevifolia, producing the billion dollar anti-cancer drug taxol [6]. Numerous bioactive molecules have been isolated from endophytic fungi since this groundbreaking discovery [7,8]. Endophytes are metabolically more active than their free counterparts due to their specific functions in nature and activation of various metabolic pathways needed to survive in the host tissues $[4,9,10]$. Therefore, investigation of endophytic fungi from medicinal plants used to treat malaria can lead to new antimalarial drug discovery.

Symphonia globulifera L. f., an evergreen tree of the Clusiaceae family, is widely distributed in Central and South America, and in tropical Africa, from Sierra Leone to Uganda, Zambia, and Angola. In traditional medicine, a decoction of leaves from this plant is used to manage malaria and several other diseases, including diabetes and skin diseases [11]. In addition, decoctions and extracts of bark are used as diuretics and antiparasitics, and to treat river blindness, chest complaints, cough in children, gonorrhea, scabies, intestinal worms, and prehepatic jaundice [12,13]. Therefore, the present study was designed to investigate for the first time antiplasmodial activity of endophytic fungi isolated from the bark of S. globulifera.

\section{Materials and Methods}

\subsection{Collection of Plant Material}

Healthy and mature stem bark of Symphonia globulifera L. f. was collected at Nomayos in the Centre Region of Cameroon in January 2015, and was identified at the National Herbarium of Cameroon, where a voucher specimen was deposited under the number 32192/HNC. Plant material was directly brought to the laboratory in sterile bags and processed within a few hours after sampling. 


\subsection{Isolation of Endophytic Fungi}

Stem bark was rinsed with tap water and cut into small pieces, approximately $5 \mathrm{~mm}$ length. Sterilization was assessed by means of a $5 \mathrm{~min}$ rinse with ethanol, followed by treatment with a $1 \%$ active chlorine solution for $15 \mathrm{~min}, 2 \mathrm{~min}$ in ethanol, and a final rinse in sterile water [14].

After surface sterilization, six plates of potato dextrose agar (PDA) supplemented with chloramphenicol $\left(200 \mathrm{mg} \cdot \mathrm{L}^{-1}\right)$, each containing 15 pieces of individual plant material, were prepared and kept in the dark at room temperature $\left(22-26^{\circ} \mathrm{C}\right)$. Fragments of mycelium emerging from plant pieces were transferred to new PDA plates without chloramphenicol to obtain pure cultures for identification. To assess whether disinfection methods were effective in eliminating surface fungi, imprints of treated fragments were made by pressing them against the surface of fresh PDA plates that were incubated without plant parts. These plates were checked for fungi emerging from the prints [14].

\subsection{Identification of Endophytic Fungi}

Fungal cultures were maintained at room temperature (i.e., $22-26^{\circ} \mathrm{C}$ ) under a natural photoperiod for 10-21 days and then examined visually for macroscopic (i.e., morphology, size, and coloration of the mycelium and agar media) and microscopic (i.e., presence of spores or other reproductive structures) characteristics. Colonies were analyzed with respect to their average diameter, sporulation, and the size and coloration of the conidia. Isolates having similar culture characteristics were grouped into morphotypes. From morphotype groups, only one isolate was processed for further identification.

Identification of endophytic isolates representative of each morphotype was based on the nucleotide sequence of the ITS1-5.8S rRNA-ITS2 region. DNA was extracted from samples of mycelium from the fungal cultures using a commercial kit (RedExtract-N-Amp Plant PCR, Sigma Aldrich, USA). The ITS1-5.8S rRNA-ITS2 region was amplified in a polymerase chain reaction (PCR) using primers ITS4 and ITS5 and the protocol described by White et al. [15]. Amplicons were purified by filtration (MSB Spin PCRapace, Invitek, Germany) and sequenced.

The FASTA algorithm was used to find sequences similar to those obtained from fungal isolates. The criteria for identification of isolates were based on the similarity of their sequences to those of reliable reference isolates included in public nucleotide databases. To visualize the diverse fungal taxa identified sequences, a dendrogram was made with the ITS1-5.8S rRNA-ITS2 nucleotide sequences of the isolates and those of reference strains deposited in CBS (Centraalbureau voor Schimmelcultures), ATCC (American Type Culture Collection), or other fungal collections, as well as some used in published works of fungal taxonomy. Sequences were aligned using the Clustal X 2.1, and the dendrogram was made with MEGA 6.06 software using the neighbor-joining method with Kimura 2-parameter distances. Groups of sequences at close proximity within the same branch of the dendrogram were individually aligned with Clustal X 2.1 to determine their percentage of similarity. Sequences with a similarity greater than $99 \%$ were considered to belong to the same species [14].

\subsection{Fermentation and Extraction}

Each fungus was cultivated on $2 \mathrm{~kg}$ of rice by placing agar blocks of actively growing pure culture ( $3 \mathrm{~mm}$ in diameter) in a $1000 \mathrm{~mL}$ Erlenmeyer flask. Each flask was incubated at $25 \pm 2{ }^{\circ} \mathrm{C}$ for 30 days. After incubation, moldy rice was macerated with ethyl acetate and filtered through three layers of muslin cloth. The organic phase was collected and the solvent was then removed by evaporation under reduced pressure at $40^{\circ} \mathrm{C}$ using a rotary vacuum evaporator. The dry solid residues were examined for their antiplasmodial activity and cytotoxicity. 


\subsection{Biological Assays}

\subsubsection{In Vitro Cultivation of Plasmodium falciparum}

A chloroquine-resistant PfINDO strain of P. falciparum was maintained in a continuous culture following the method of Trager \& Jensen, 1976 [16] with minor modifications. Cultures were maintained in fresh $\mathrm{O}$ positive human erythrocytes suspended at $4 \%(v / v)$ haematocrit in complete medium (16.2 g. $\mathrm{L}^{-1}$ RPMI 1640 (Sigma) containing $25 \mathrm{mM}$ HEPES, $11.11 \mathrm{mM}$ glucose, $0.2 \%$ sodium bicarbonate (Sigma), 0.5\% Albumax I (Gibco), $45 \mathrm{mg} \cdot \mathrm{L}^{-1}$ hypoxanthine (Sigma), and $50 \mathrm{mg} \cdot \mathrm{L}^{-1}$ gentamicin (Gibco)) and incubated at $37{ }^{\circ} \mathrm{C}$ in a gas mixture consisting of $5 \% \mathrm{O}_{2}, 5 \% \mathrm{CO}_{2}$, and $90 \% \mathrm{~N}_{2}$. The spent medium was replaced with fresh complete medium every day to propagate the culture. Giemsa-stained blood smears were examined microscopically to monitor cell cycle transitions and parasitemia.

\subsubsection{Preparation of Stock Solution of Chloroquine and Fungal Extracts}

Stock solutions of fungal extracts were prepared in Dimethyl sulfoxide (DMSO) at $25 \mathrm{mg} \cdot \mathrm{mL}^{-1}$ and that of chloroquine phosphate (CQ) (Sigma) was prepared at $1 \mathrm{mM}$ in Milli-Q grade water. The required drug concentrations were achieved by diluting the stocks with incomplete RPMI (Roswell Park Memorial Institute) 1640 medium. The solutions of drugs and extracts were placed in 96-well flat-bottom tissue culture grade plates (Corning). For each extract, the concentrations $\left(\mu \mathrm{g} \cdot \mathrm{mL}^{-1}\right)$ tested were $0.195,0.39,0.78,1.562,3.125,6.25,12.5,25,50$, and 100 .

\subsubsection{In Vitro Antiplasmodial Assay}

Before each experiment, synchronized ring stage parasites were obtained by $5 \%(w / v)$ sorbitol treatment [17]. It is important to note that use of synchronized cultures over mixed-stage cultures can enable the test molecules to interact with all three stages (i.e., ring, trophozoite, and schizont) of the $48 \mathrm{~h}$ long life cycle of P. falciparum in culture. Moreover, starting the experiment with synchronized ring stage culture provides the distinct advantage of observing growth inhibitory effects without a rise in parasitemia during the ring-trophozoite-schizont transitions.

For drug screening, the SYBR green I based fluorescence assay was used [18]. The ability of SYBR green to give strong fluorescence only in the presence of DNA forms the basis for its use to assess cell proliferation. The absence of a nucleus in human red blood cells where the malaria parasite proliferates allows the use of SYBR green for the specific monitoring of the growth of malarial parasite.

Sorbitol-synchronized ring stage parasites (haematocrit: $2 \%$, parasitemia: $1 \%, 96 \mu \mathrm{L}$ ) under normal culture conditions were incubated in the presence or absence of increasing concentrations of the extracts. Four $\mu \mathrm{L} \mathrm{CQ}(1 \mathrm{mM})$ was used as a positive control and $0.4 \%$ DMSO $(v / v)$, which was found to be non-toxic to the parasite, was used as vehicle control. After $48 \mathrm{~h}$ of incubation, $100 \mu \mathrm{L}$ of SYBR Green I buffer $\{0.2 \mu \mathrm{L}$ of $10,000 \times$ SYBR Green I (Invitrogen) per mL of lysis buffer (Tris (20 mM; pH 7.5), EDTA (5 mM), saponin $(0.008 \% ; w / v)$, and Triton X-100 $(0.08 \% ; v / v)\}$ was added to each well, mixed twice gently with multi-channel pipette and incubated in the dark at $37^{\circ} \mathrm{C}$ for $1 \mathrm{~h}$. Fluorescence was measured using a Victor fluorescence multi-well plate reader (Perkin Elmer) with excitation and emission at 485 and $530 \mathrm{~nm}$, respectively. Fluorescence counts for CQ representing zero growth were deducted from counts in each well. A dose-response curve was constructed by plotting fluorescence counts against the drug concentration and $\mathrm{IC}_{50}$ (dose of a drug required to retard the growth of a cell population by 50\%) was determined using IC Estimator-version 1.2 (http:/ / www.antimalarial-icestimator.net/MethodIntro.htm). In this experiment, no drug (control) corresponds to $100 \%$ growth while $40 \mu \mathrm{M}$ chloroquine (sufficient to cause total arrest of growth) corresponds to $0 \%$ growth. Giemsa-stained smears of extract-treated parasite cultures were visualized microscopically to validate the results from fluorescence-based assay. Experiments were done in triplicate and means with standard deviation were calculated. Extracts were classified according to criteria of the antiplasmodial activity based upon $\operatorname{good}\left(\mathrm{IC}_{50}<10 \mu \mathrm{g} \cdot \mathrm{mL}^{-1}\right)$, moderate $\left(\mathrm{IC}_{50}>10\right.$ to $\left.<25 \mu \mathrm{g} \cdot \mathrm{mL}^{-1}\right)$, and inactive $\left(\mathrm{IC}_{50}>25 \mu \mathrm{g} \cdot \mathrm{mL}^{-1}\right)$ activity as proposed by Bagavan et al. [19]. 


\subsubsection{Cytotoxicity Assay}

The cytotoxic effects of the most potent crude extracts were determined by a functional assay [20] using the human embryonic kidney HEK239T cells cultured in complete medium containing $16.2 \mathrm{~g} \cdot \mathrm{L}^{-1}$ DMEM, $10 \%$ fetal bovine serum, $0.2 \%$ sodium bicarbonate $(w / v)\left(\right.$ Sigma), and $50 \mu \mathrm{g} \cdot \mathrm{mL}^{-1}$ gentamycin. Cells $\left(5 \times 10^{3}\right.$ cells $/ 200 \mu \mathrm{L} /$ well $)$ were seeded into 96 -well flat-bottom tissue culture plates in complete medium. After $24 \mathrm{~h}$ of cells seeding, test extracts were added and cells incubated for $48 \mathrm{~h}$ in a humidified atmosphere at $37{ }^{\circ} \mathrm{C}$ and $5 \% \mathrm{CO}_{2}$. DMSO (as positive inhibitor) was added at $10 \% \mathrm{v} / \mathrm{v}$. Twenty microliters of a stock solution of MTT [3-(4,5-dimethylthiazol-2-yl)-2,5-diphenyltetrazolium bromide] ( $5 \mathrm{mg} \cdot \mathrm{mL}^{-1}$ in $1 \times$ phosphate buffered saline) was added to each well, gently mixed, and incubated for another $4 \mathrm{~h}$. The supernatant was thereafter removed and $100 \mu \mathrm{L}$ DMSO (quench agent) was added to the cell pellet. Formazan formation was measured using a microtiter plate reader (VersaMax tunable multiwell plate reader) at $570 \mathrm{~nm}$. The $50 \%$ cytotoxic concentration $\left(\mathrm{CC}_{50}\right)$ of drugs was determined by analysis of dose-response curves. Selectivity index $\left(\mathrm{CC}_{50} / \mathrm{IC}_{50}\right)$ was calculated for each extract (tested in triplicate).

\section{Results}

\subsection{Isolation and Identification of Fungi}

From a total of 90 fragments of the stem bark of Symphonia globulifera, 61 isolates were obtained with an infection frequency of $67.77 \%$. They were subsequently grouped into 14 morphotypes and one isolate from each morphotype was identified by sequence analysis of the Internal Transcribed Spacer (ITS) region. Twelve analyzed isolates were classified into six different genera including, Fusarium, Paecilomyces, Penicillium, Aspergillus, Mucor, and Bipolaris (Table 1; Figure 1). The most representative genera were Fusarium and Penicillium (Table 1).

Table 1. Identification of endophyte isolates and percentage homology of sequences.

\begin{tabular}{ccc}
\hline Endophyte Isolates & \% Sequence Homology & $\begin{array}{c}\text { Organism with the Highest Sequence Identity, } \\
\text { GenBank Acc. No. }\end{array}$ \\
\hline Fusarium decemcellulaire & 98 & Fusarium decemcellulaire KM231809 \\
\hline Paecilomyces sp. & 100 & Paecilomyces sp. FJ196762 \\
\hline Fusarium oxysporum & 100 & Fusarium oxysporum KT794176 \\
\hline Paecilomyces lilacinus & 100 & Paecilomyces lilacinus GU980023 \\
\hline Penicillium janthinellum & 99 & Penicillium janthinellum AY373921 \\
\hline Aspergillus tamarri & 100 & Aspergillus tamarri HQ340111 \\
\hline Penicilium sp. (1) & 99 & Penicillium sp. JN021538 \\
\hline Bipolaris sorokiniana & 94 & Bipolaris sorokiniana KU194490 \\
\hline Fusarium lateritium & 94 & Fusarium lateritium KC453998 \\
\hline Penicillium sp. (2) & 98 & Penicillium sp. JN021538 \\
\hline Aspergillus aculeatus & 100 & Aspergillus aculeatus AY585556 \\
\hline Mucor falcatus & 89 & Mucor falcatus NR103647 \\
\hline
\end{tabular}




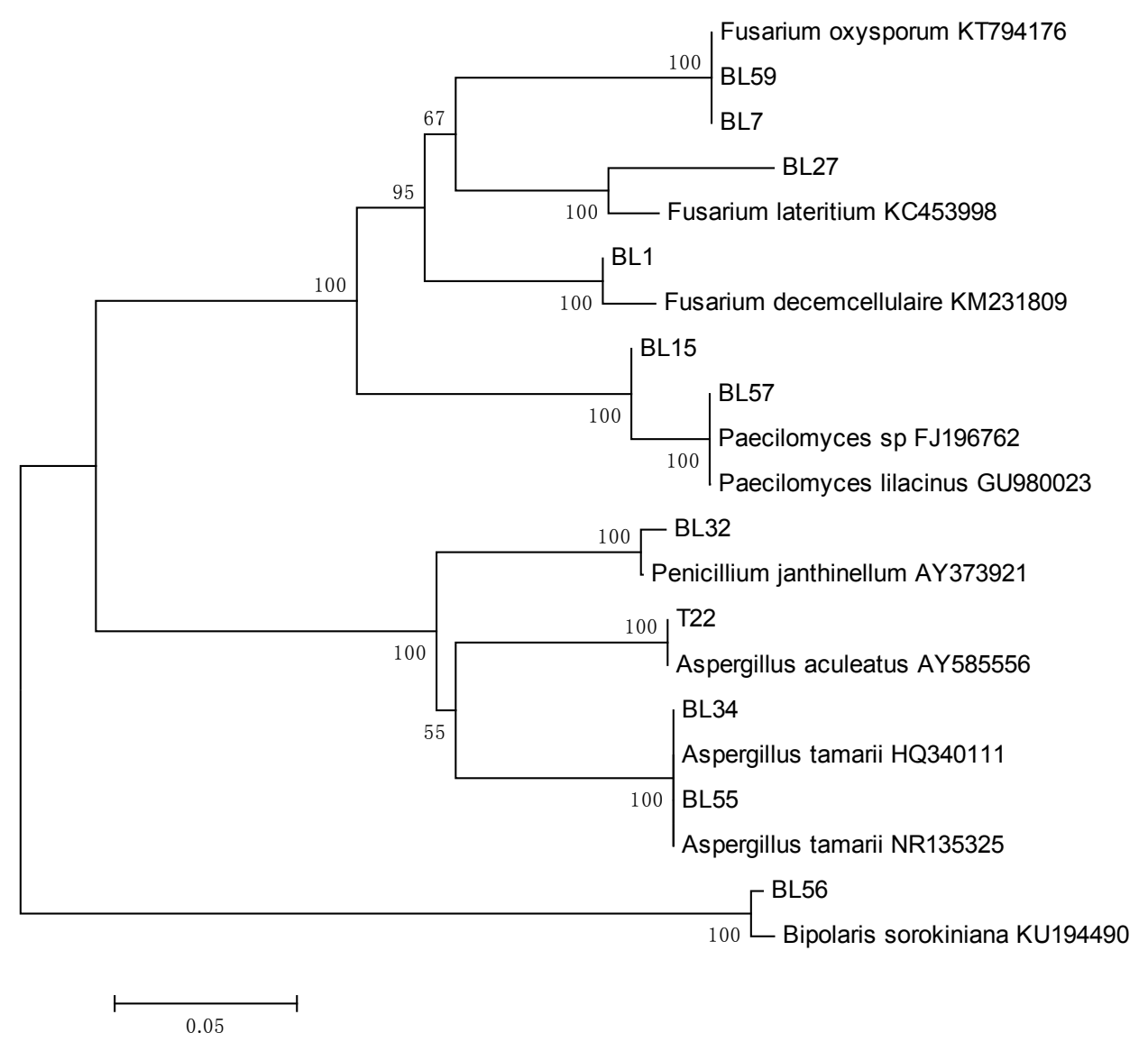

Figure 1. Classification of fungal endophytes isolated from Symphonia globulifera based on a neighbor-joining phylogenetic tree made with ITS1-5.8S rDNA-ITS2 nucleotide sequences. Taxa with accession numbers correspond to reference strains. Numbers at branch nodes are bootstrap values based on 500 replications.

\subsection{In Vitro Antiplasmodial Activity of Endophytic Extracts}

Twelve endophytic fungi were cultured in a rice medium at $25 \pm 2{ }^{\circ} \mathrm{C}$ for 30 days and subsequently extracted using ethyl acetate as a solvent. The extraction yields ranged from $6.30 \mathrm{~g}$ to $21.70 \mathrm{~g}$ with A. tamarri producing the higher yield.

The $\mathrm{IC}_{50}$ of the tested extracts against the chloroquine-resistant Plasmodium falciparum INDO (PfINDO) strain ranged from 0.2 to $>100 \mu \mathrm{g} \cdot \mathrm{mL}^{-1}$ (Table 2). Out of the 12 tested extracts, nine showed good activity $\left(\mathrm{IC}_{50}<10 \mu \mathrm{g} \cdot \mathrm{mL}^{-1}\right)$. Extracts from Paecilomyces lilacinus, Penicillium janthinellum, and Paecilomyces sp. exerted highly potent activities with $\mathrm{IC}_{50}<1 \mu \mathrm{g} / \mathrm{mL}$. Extracts from Mucor falcatus and Aspergillus aculeatus showed moderate potency with $\mathrm{IC}_{50}$ between 10 and $25 \mu \mathrm{g} \cdot \mathrm{mL}^{-1}$, while the extract from Aspergillus tamarri with $\mathrm{IC}_{50}>100 \mu \mathrm{g} \cdot \mathrm{mL}^{-1}$ was considered as inactive.

\subsection{Cytotoxicity of Extracts}

The cytotoxicity of the extracts was tested against HEK239T cells. As shown in Table 2, $\mathrm{CC}_{50}$ values ( $\mu \mathrm{g} \mathrm{mL}^{-1}$ ) ranged from 3.06 to 70.91 leading selectivity indices to lie between 0.5 and 70.56 . Penicillium sp. (2). ( $\mathrm{SI}=0.69)$, Bipolaris sorokiniana ( $\mathrm{SI}=0.504)$, and Penicilliun sp. (1) ( $\mathrm{SI}=0.842)$ were found to be highly cytotoxic against HEK239T cells. Conversely, the most potent fungal extracts from Paecilomyces lilacinus $\left(\mathrm{CC}_{50}=10.79 \mu \mathrm{g} \mathrm{mL}{ }^{-1} ; \mathrm{SI}=24.52\right)$, Penicillium janthinellum $\left(\mathrm{CC}_{50}=9.14 \mu \mathrm{g} \mathrm{mL}^{-1}\right.$; $\mathrm{SI}=45.7)$, and Paecilomyces sp. $\left(\mathrm{CC}_{50}=38.88 \mu \mathrm{g} \mathrm{mL}^{-1}\right.$; $\left.\mathrm{SI}=70.56\right)$ were less cytotoxic. 
Table 2. Antiplasmodial and cytotoxic activities of extracts of endophytic fungi from the bark of Symphonia globulifera.

\begin{tabular}{|c|c|c|c|c|}
\hline Sample & $\begin{array}{l}\text { Dry Mass of } \\
\text { Extract (g) }\end{array}$ & $\begin{array}{c}\mathrm{IC}_{50} \text { against } P f I N D O \\
\text { Strain }\left(\mu \mathrm{g} \cdot \mathrm{mL}^{-1} \pm \mathrm{SD}\right)\end{array}$ & $\begin{array}{l}\mathrm{CC}_{50} \text { against } H E K 239 T \\
\text { Cells }\left(\mu \mathrm{g} \cdot \mathrm{mL}^{-1} \pm \mathrm{SD}\right)\end{array}$ & SI $\left(\mathrm{CC}_{50} / \mathrm{IC}_{50}\right)$ \\
\hline Fusarium decemcellulaire & 10.81 & $2.19 \pm 0.07$ & $70.91 \pm 0.18$ & 32.37 \\
\hline Paecilomyces sp. & 14.66 & $0.55 \pm 0.01$ & $38.81 \pm 0.19$ & 70.56 \\
\hline Fusarium oxysporum & 8.23 & $1.70 \pm 0.22$ & $18.24 \pm 0.11$ & 10.729 \\
\hline Paecilomyces lilacinus & 6.20 & $0.44 \pm 0.03$ & $10.79 \pm 0.2$ & 24.52 \\
\hline Penicillium janthinellum & 6.30 & $0.20 \pm 0.01$ & $9.14 \pm 0.12$ & 45.7 \\
\hline Aspergillus tamarri & 21.70 & $>100$ & $* * *$ & NA \\
\hline Penicilium sp. & 14.57 & $3.63 \pm 0.02$ & $3.06 \pm 0.36$ & 0.842 \\
\hline Bipolaris sorokiniana & 9.89 & $6.10 \pm 0.37$ & $3.08 \pm 0.19$ & 0.504 \\
\hline Fusarium lateritium & 11.67 & $6.61 \pm 0.01$ & $2.82 \pm 0.23$ & 0.426 \\
\hline Penicillium sp.(2) & 16.32 & $9.08 \pm 0.13$ & $6.28 \pm 1.23$ & 0.69 \\
\hline Aspergillus aculeatus & 8.74 & $22.08 \pm 0.43$ & $* * *$ & NA \\
\hline Mucor falcatus & 9.22 & $17.51 \pm 0.19$ & $* * *$ & NA \\
\hline Chloroquine & NA & $* 400$ & $* * *$ & NA \\
\hline
\end{tabular}

Data are presented as mean values \pm standard deviation of triplicate experiments; SD: standard deviation; ${ }^{* * *}$ : not tested; NA: not applicable. SI: Selectivity index (ratio of $\mathrm{CC}_{50}$ to $\mathrm{IC}_{50}$ ); ${ }^{*} \mathrm{IC}_{50}$ of chloroquine given in $\mathrm{nM}$.

\section{Discussion}

Endophytic fungi have been claimed to be responsible for the medicinal properties of several medicinal plants [21]. Therefore, in this study we have explored the antiplasmodial potential of endophytic fungi associated with Symphonia globulifera used in several African countries for treatment of malaria. More specifically, towards discovery of new drugs against malaria, this study was done to perform antiplasmodial screening of endophytic fungi obtained from the bark of this plant.

A high prevalence of endophyte infection of $67.77 \%$ was found in bark fragments of Symphonia globulifera. This high level of endophyte colonization is corroborated by previous findings which indicated that endophyte prevalence in some tissues of Cameroonian medicinal plants is quite high [14]. Moreover, Arnold and Lutzoni [22] reported that the prevalence of endophyte species in plant tissues of tropical regions is greater than in plant species of temperate and boreal forests. The identification based on sequence analysis indicated that all of the analyzed endophytic isolates obtained from bark of S. globulifera belong to six different genera including Fusarium, Paecilomyces, Penicillium, Aspergillus, Mucor, and Bipolaris. All these genera have also been reported in previous endophyte surveys in different plant species [14,23-26].

Although only 12 endophyte isolates were screened in the present study, as many as nine of them produced antiplasmodial compounds $[27,28]$. The finding that as high as $75 \%$ gave good activity $\left(\mathrm{IC}_{50}<10 \mu \mathrm{g} \cdot \mathrm{mL}^{-1}\right.$ ) with $33.3 \%$ (3) of this portion showing highly potent antiplasmodial activity $\left(\mathrm{IC}_{50}<1 \mu \mathrm{g} \cdot \mathrm{mL}^{-1}\right.$ ) suggests that deeper exploration of endophytic fungi may reveal a rich repertoire of antiplasmodial molecules. Previous studies reported that endophyte fungi of Penicillium and Paecilomyces species are important sources of antiplasmodial secondary metabolites [28]. In fact, $\beta$-Resorcyclic acid lactones, cyclodepsipeptides, and tropane derivatives with potent antiplasmodial activities have earlier been isolated from Paecilomyces [29-31] and Penicillium [27] species.

Our findings have indicated that endophytic fungi belonging to the genera Fusarium, Paecilomyces, Penicillium, and Bipolaris isolated from this plant species should be studied intensely for novel antiplasmodial compounds. Therefore, further studies on the antiplasmodial activity guided isolation and characterization of active metabolites produced by promising fungi necessary for the discovery of new drugs against malaria are ongoing. 


\section{Conclusions}

This study is the first report on the antiplasmodial potential of endophytic fungi from the bark of Symphonia globulifera. In this investigation, 9 out of 12 fungi showed promising antiplasmodial potency with Paecilomyces lilacinus, Penicillium janthinellum, and Paecilomyces sp. being the most promising. These results obtained in this study highlight endophytic fungi from S. globulifera as a promising source of novel lead antimalarial compounds.

Author Contributions: B.N.L., E.T., and F.F.B. conceived and designed the experiments; J.E.T.A., R.M.K.T., B.M.M., A.F.A., S.G., and B.N.L. performed the experiments; E.R.-F. analyzed the data; N.S., D.S., and B.N.L. contributed reagents/materials/analysis tools; J.E.T.A. wrote the paper.

Acknowledgments: The authors wish to acknowledge the Alexander von Humboldt Foundation for providing a fellowship to Bruno N. Lenta. The authors are also grateful to the TWAS-CNPq (The World Academy of Science-Conselho Nacional de Desenvolvimento Científico e Tecnológico) for the fellowships awarded to Brice M. Mba'ning (Award No. 190644/2015-0).

Conflicts of Interest: The authors declare no conflict of interest.

\section{References}

1. World Malaria Report 2017; Licence: CC BY-NC-SA 3.0 IGO; World Health Organization: Geneva, Switzerland, 2017.

2. D'Alessandro, U. Existing antimalarial agents and malaria-treatment strategies. Expert Opin. Pharmacother. 2009, 10, 1291-1306. [CrossRef] [PubMed]

3. Dhar, R.; Zhang, K.; Talwar, G.P.; Garg, S.; Kumar, N. Inhibition of the growth and development of asexual and sexual stages of drug-sensitive and resistant strains of the human malaria parasite Plasmodium falciparum by Neem (Azadirachta indica) fractions. J. Ethnopharmacol. 1998, 61, 31-39. [CrossRef]

4. Strobel, G.A.; Daisy, B. Bioprospecting for microbial endophytes and their natural products. Microbiol. Mol. Biol. Rev. 2003, 67, 491-502. [CrossRef] [PubMed]

5. Porras-Alfaro, A.; Bayman, P. Hidden fungi, emergent properties: Endophytes and microbiomes. Ann. Rev. Phytopathol. 2011, 49, 291-315. [CrossRef] [PubMed]

6. Stierle, A.; Strobel, G.A.; Stierle, D.B. Taxol and taxane production by Taxomyces andreanae, an endophytic fungus of Pacific yew. Science 1993, 260, 214-216. [CrossRef] [PubMed]

7. Wang, L.W.; Zhang, Y.L.; Lin, F.C.; Hu, Y.Z.; Zhang, C.L. Natural products with antitumor activity from endophytic fungi. Mini Rev. Med. Chem. 2011, 11, 1056-1074. [CrossRef] [PubMed]

8. Zhang, Y.; Han, T.; Ming, Q.; Wu, L.; Rahman, K.; Qin, L. Alkaloids produced by endophytic fungi: A review. Nat. Prod. Commun. 2012, 7, 963-968. [PubMed]

9. Strobel, G. Harnessing endophytes for industrial microbiology. Curr. Opin. Microbiol. 2006, 9, 240-244. [CrossRef] [PubMed]

10. Riyaz-Ul-Hassan, S.; Strobel, G.A.; Booth, E.; Knighton, B.; Floerchinger, C.; Sears, J. Modulation of volatile organic compound formation in the Mycodiesel producing endophyte- Hypoxylon sp. C1-4. Microbiology 2012, 158, 464-473. [CrossRef]

11. Ajibesin, K.; Ekpo, B.; Bala, D.; Essien, E.; Adesanya, S. Ethnobotanical survey of Akwalbom State of Nigeria. J. Ethnopharmacol. 2008, 115, 387-408. [CrossRef] [PubMed]

12. Ssegawa, P.; Kasenene, J.M. Medicinal plant diversity and uses in the Sango bay area, Southern Uganda. J. Ethnopharmacol. 2007, 113, 521-540. [CrossRef] [PubMed]

13. Fromentin, Y.; Cottet, K.; Kritsanida, M.; Miche, S.; Gaboriaud-Kolar, N.; Lallemand, M.-C. Symphoniaglobulifera, a widespread Source of Complex Metabolites with Potent Biological Activities. Planta Med. 2015, 81, 95-107. [CrossRef] [PubMed]

14. Toghueo, R.M.K.; Zabalgogeazcoa, I.; Vázquez de Aldana, B.R.; Boyom, F.F. Enzymatic activity of endophytic fungi from the medicinal plants Terminalia catappa, Terminalia mantaly and Cananga odorata. S. Afr. J. Bot. 2017, 109, 146-153. [CrossRef]

15. White, T.J.; Bruns, T.; Lee, S.; Taylor, J. Amplification and Direct Sequencing of Fungalribosomal RNA Genes for Phylogenetics. In PCR Protocols. A Guide to Methods and Applications; Innis, M.A., Gelfland, D.H., Sninsky, J.J., White, T.J., Eds.; Academic Press: Cambridge, MA, USA, 1990; pp. 315-322. 
16. Trager, W.; Jensen, J.B. Human malaria parasites in continuous culture. Science 1976, 193, 673-675. [CrossRef] [PubMed]

17. Lambros, C.; Vanderberg, J.P. Synchronization of Plasmodium falciparum erythrocytic stages in culture. J. Parasitol. 1979, 65, 418-420. [CrossRef] [PubMed]

18. Smilkstein, M.; Sriwilaijaroen, N.; Kelly, J.X.; Wilairat, P.; Riscoe, M. Simple and inexpensive fluorescence-based techniquefor high-throughput antimalarial drug screening. Antimicrob. Agents Chemother. 2004, 48, 1803-1806. [CrossRef] [PubMed]

19. Bagavan, A.; Rahuman, A.A.; Kumaraj, C.; Kaushik, N.K.; Mohanahrishnan, D.; Sahal, D. Antiplasmodial activity of botanical extracts against Plasmodium falciparum. Parasitol. Res. 2011, 108, 1099-1109. [CrossRef] [PubMed]

20. Mosmann, T. Rapid colorimetric assay for cellular growth and survival: Application to proliferation and cytotoxicity assays. J. Immunol. Methods 1983, 65, 55-63. [CrossRef]

21. Zou, W.X.; Meng, J.C.; Lu, H.; Chen, G.X.; Shi, G.X.; Zhang, T.Y.; Tan, R.X. Metabolites of Colletotrichum gloeosporioides, an endophytic fungus in Artemisia mongolica. J. Nat. Prod. 2000, 63, 1529-1530. [CrossRef] [PubMed]

22. Arnold, A.E.; Lutzoni, F. Diversity and host range of foliar fungal endophytes: Are tropical leaves biodiversity hotspots? Ecology 2007, 88, 541-549. [CrossRef] [PubMed]

23. Sánchez, M.S.; Bills, G.F.; Zabalgogeazcoa, I. The endophytic mycobiota of the grass Dactylis glomerata. Fungal Divers. 2007, 27, 171-195.

24. Sun, X.; Ding, Q.; Hyde, H.D.; Guo, L.D. Community structure and preference of endophytic fungi of three woody plants in a mixed forest. Fungal Ecol. 2012, 5, 624-632. [CrossRef]

25. Felber, C.A.; Orlandelli, C.R.; Rhoden, S.A.; Garcia, A.; Costa, A.T.; Azevedo, J.L.; Pamphile, J.A. Bioprospecting foliar endophytic fungi of Vitisla brusca L., cv. Bordô and Concord. Ann. Microbiol. 2015, 26, 765-775. [CrossRef]

26. Arnold, A.E.; Maynard, Z.; Gilbert, G.S.; Coley, P.D.; Kursar, T.A. Are tropical fungal endophytes hyperdiverse? Ecol. Lett. 2000, 3, 267-274. [CrossRef]

27. Iwatsuki, M.; Takada, S.; Mori, M.; Ishiyama, A.; Namatame, M.; Nishihara-Tsukashima, A.; Nonaka, K.; Masuma, R.; Otoguro, K.; Shiomi, K.; et al. In vitro and in vivo antimalarial activity of puberulic acid and its new analogs, viticolins A-C, produced by Penicillium sp. FKI-4410. J. Antibiot. 2011, 64, 183-188. [CrossRef] [PubMed]

28. Kaushik, N.K.; Murali, T.S.; Sahal, D.; Suryanarayanan, T.S. A search for antiplasmodial metabolites among fungal endophytes of terrestrial and marine plants of southern India. Acta Parasitol. 2014, 59, 745-757. [CrossRef] [PubMed]

29. Xu, L.; He, Z.; Xue, J.; Chen, X.; Wei, X. B-Resorcyclic acid lactones from a Paecilomyces fungus. J. Nat. Prod. 2010, 73, 885-889. [CrossRef] [PubMed]

30. Isaka, M.; Palasarn, S.; Lapanun, S.; Sriklung, K. Paecilodepsipeptide A, an antimalarial and antitumor cyclohexadepsipeptide from the insect pathogenic fungus Paecilomyces cinnamomeus BCC 9616. J. Nat. Prod. 2007, 70, 675-678. [CrossRef] [PubMed]

31. Nilanonta, C.; Isaka, M.; Kittakoop, P.; Palittapongarnpim, P.; Kamchonwongpaisan, S.; Pittayakhajonwut, D.; Tanticharoen, M.; Thebtaranonth, Y. Antimycobacterial and antiplasmodial cyclodepsipetides fron the insect pathogenic fungus Paecilomyces tenuipes BCC 1614. Planta Med. 2000, 66, 756-758. [CrossRef] [PubMed]

(C) 2018 by the authors. Licensee MDPI, Basel, Switzerland. This article is an open access article distributed under the terms and conditions of the Creative Commons Attribution (CC BY) license (http:/ / creativecommons.org/licenses/by/4.0/). 